\title{
Rehabilitation after surgical treatment of peroneal tendon tears and ruptures
}

\author{
Pim A. D. van Dijk $k^{1,2,3,4} \cdot$ Bart Lubberts $^{4}$ - Claire Verheul, ${ }^{2,3,5}$ • \\ Christopher W. DiGiovanni ${ }^{4}$ - Gino M. M. J. Kerkhoffs ${ }^{1,2,3}$
}

Received: 8 October 2015 / Accepted: 9 December 2015 / Published online: 23 January 2016

(C) The Author(s) 2016. This article is published with open access at Springerlink.com

\begin{abstract}
Purpose The purpose of this study was to provide an overview of the available evidence on rehabilitation programmes after operatively treated patients with peroneal tendon tearsand ruptures.

Methods A systematic review was performed, and PubMed and EMBASE were searched for relevant studies. Information regarding the rehabilitation programme after surgical management of peroneal tendon tears and ruptures was extracted from all included studies.

Results In total, 49 studies were included. No studies were found with the primary purpose to report on rehabilitation of surgically treated peroneal tendon tears or ruptures. The median duration of the total immobilization period after primary repair was 6.0 weeks (range 0-12), 7.0 weeks (range 3.0-13) after tenodesis, 6.3 weeks (range 3.0-13) after grafting, and 8.0 weeks (range 6.0-11) after
\end{abstract}

Pim A. D. van Dijk

p.a.vandijk@amc.uva.nl

Gino M. M. J. Kerkhoffs

g.m.kerkhoffs@amc.uva.nl

1 Department of Orthopaedic Surgery, Orthopaedic Research Center Amsterdam, Academic Medical Center, University of Amsterdam, Meibergdreef 9, 1105 AZ Amsterdam, The Netherlands

2 Academic Center for Evidence Based Sports Medicine (ACES), Amsterdam, The Netherlands

3 Amsterdam Collaboration on Health and Safety in Sports (ACHSS), Amsterdam, The Netherlands

4 Foot and Ankle Service, Department of Orthopaedic Surgery, Massachusetts General Hospital, Boston, MA, USA

5 Orthopaedic Manual Therapy and (Sport)Physiotherapy, ManualFysion, Amsterdam, The Netherlands end-to-end suturing. Forty one percent of the studies that reported on the start of range of motion exercises initiated range of motion within 4 weeks after surgery. No difference was found in duration of immobilization or start of range of motion between different types of surgical treatment options.

Conclusion Appropriate directed rehabilitation appears to be an important factor in the clinical success of surgically treated peroneal tendon tears and ruptures. There seems to be a trend towards shorter immobilization time and early range of motion, although there is no consensus in the literature on best practice recommendations for optimizing rehabilitation after surgical repair of peroneal tendon tears or ruptures. It is important to adjust the rehabilitation protocol to every specific patient for an optimal rehabilitation. Level of evidence Systematic Review, Level IV.

Keywords Physical therapy $\cdot$ Rehabilitation $\cdot$ Peroneal tendon $\cdot$ Tear $\cdot$ Tendon $\cdot$ Rupture $\cdot$ Tendon healing

\section{Introduction}

Lateral ankle sprains are among the most common acute musculoskeletal injuries [9] and can result in peroneal tendon disorders, particularly peroneus brevis tendon tears. The exact prevalence of these tears in general population remains unknown, but cadaveric studies have shown a prevalence of $11-38 \%[32,57]$. Surgical treatment is essential to prevent deterioration of tendon tissue and chronic pain complaints [13, 25, 46, 64]. To our knowledge, there is no consensus in the available literature regarding appropriate after-treatment of surgically treated peroneal tendon tears.

Acute ankle inversion injury is a typical trigger for a peroneal tendon tear. Chronic lateral ankle instability with 
repetitive sprains, repetitive stress or overuse, peroneal tendon subluxation, or anatomic abnormalities can also provoke tears $[17,25,51,55,58,59,64]$. Patients often present with undefined lateral ankle pain or lateral ankle giving way complaints and typically demonstrate recognizable pain on palpation located over the posterior part of the distal fibula, worsened by activity [64].

Injury of the peroneal tendons can be debilitating for patients. Prompt diagnosis is the first step in the pathway of treating peroneal tendon tears. Depending on the severity of the pathology, different surgical treatment options are proposed $[25,46]$. When less then $50 \%$ of the crosssectional tendon is involved, tears are often treated with debridement and tubularization of the tendon. Involvement of more then $50 \%$ of the cross-sectional tissue may necessitate tenodesis to the adjacent intact peroneal tendon when it remains functional, or grafting when both tendons are found to be non-functional [25, 46, 64]. In the case of an acute complete rupture, both ends may be sutured together, although in chronic cases some form of tenodesis or tendon interposition is required to restore peroneal integrity. In symptomatic patients, surgical treatment has been associated with improved return to full activity and improvement in patients-reported outcome scores [13].

To optimize recovery of surgically treated peroneal tendon tears and ruptures, an appropriate rehabilitation programme is necessary. Facilitation of early return to activity is of great importance, since peroneal tendon tears are mostly found in active patients and athletes. Both nonweight-bearing immobilization (NWB) and weight-bearing immobilization (WB) are used in the rehabilitation process to facilitate an optimal recovery while preventing re-injuries. Since flexor tendons tend to form adhesions between the repaired tissue and surrounding scar tissue after surgical repair, early range of motion (ROM) is recommended in several tendon pathologies [18]. No evidence can be found, however, as to specifically when to begin ROM exercises following surgical repair of peroneal tendon tears and ruptures.

The aim of this study is to create an overview of available best practice evidence in the current literature with respect to rehabilitation options following surgical treatment of peroneal tendon tears and ruptures.

\section{Materials and methods}

\section{Search strategy}

Searching PubMed/MEDLINE and EMBASE electronic databases identified relevant literature. Three keywords (peroneal, tendon and tear) and related synonyms were used. All synonyms were combined with the Boolean command AND and were linked by the Boolean command OR. The last search was performed on 25 June 2015.

\section{Eligibility criteria}

Original studies were included if (1) the study reported on peroneal tendon tears or ruptures, (2) the rehabilitation process after surgical treatment was described, (3) duration of immobilization was described, (4) the study was published after December 1994, and (5) full text was available in English.

\section{Study selection}

Two authors (PAD, BL) performed the literature search and independently reviewed the search results. Titles and abstracts were reviewed by applying strict inclusion criteria for study characteristics as described above. Consensus for studies to be included was achieved by discussion between the two reviewers based on the predetermined selection criteria. Identified articles were reviewed on full text, and each reference list was screened for additional citation tracking.

\section{Data extraction}

All data items were predetermined and specified as shown in Table 1. Two authors performed data extraction independently, using a modified extraction form. Duration of immobilization was described and rounded in weeks.

\section{Statistical analysis}

Descriptive statistics including means and standard deviations were calculated for each variable. One-way ANOVA was used for the comparison of group means in duration of immobilization and time of start with ROM exercises, and post hoc analyses using Bonferroni correction were employed. A $p$ value of less than 0.083 (0.05 divided by 6) was considered as statistically significant. Statistical analysis was performed using Stata (version 13.0, STATA Corp., TX, USA).

\section{Results}

The literature search in PubMed/MEDLINE and EMBASE databases yielded, respectively, 421 and 299 records. After duplicates were removed, 532 studies were included for title and abstract review. Careful systematic selection resulted in 49 studies eligible for this review; 24 case reports, 8 reviews, and 17 case series (Fig. 1). No studies were found with the primary focus on rehabilitation of surgically treated peroneal tendon tears or ruptures. Included studies described their rehabilitation method after one or more of the following 
Table 1 Baseline characteristics

\begin{tabular}{|c|c|c|c|c|c|}
\hline Study & Study design & Treatment & NWB in weeks & WB (partial) in weeks & Start ROM (weeks) \\
\hline Arbab et al. [1] & II & A, B, D & 2 & 4 & 6 \\
\hline Bare et al. [2] & II & A, B & 4 & 4 & 5 \\
\hline Berg et al. [4] & III & $\mathrm{D}$ & 2 & 6 & - \\
\hline Blitz and Nemes [5] & III & B & 8 & 2 & 2 \\
\hline Bonnin et al. [6] & II & A & 0 & 6,5 & - \\
\hline Borland et al. [7] & III & A & 6 & 0 & 6 \\
\hline Borton et al. [8] & III & $\mathrm{C}$ & 6 & 0 & 6 \\
\hline Cerrato et al. [10] & I & $\mathrm{B}, \mathrm{C}$ & 2 & $4-6$ & 2 \\
\hline De Yoe et al. [12] & III & A & 4 & 2 & 4 \\
\hline Demetracopoulos et al. [13] & II & A & 2 & 2 & 4 \\
\hline Dombek et al. [14] & II & A, B & $4-5$ & $2-3$ & 4 \\
\hline Fujioka et al. [16] & III & B & 2 & 2 & 2 \\
\hline Ho. et al. [19] & III & A & 6 & 6 & 6 \\
\hline Jockel et al. [21] & II & $\mathrm{C}$ & 8 & 4 & 12 \\
\hline Karlsson et al. [24] & II & A & 0 & 6 & 6 \\
\hline Karlsson and Wiger [23] & I & A & 0 & 6 & 2 \\
\hline Krause and Brodsky [25] & II & A, B & 5 & $1-8$ & 5 \\
\hline Lagoutaris et al. [26] & III & A & 4 & 0 & 4 \\
\hline Lucas et al. [27] & III & A & 2 & 4 & 6 \\
\hline Lui et al. [28] & I & A & 4 & 0 & - \\
\hline \multirow[t]{2}{*}{ Maurer and Lehrman [30] } & III & $\mathrm{B}$ & 6 & 3 & 5 \\
\hline & III & B & 6 & 2 & 2 \\
\hline Madsen et al. [29] & III & $C+D$ & 8 & 0 & - \\
\hline Minoyama et al. [31] & III & A & 2 & 2 & - \\
\hline Mook et al. [34] & II & $\mathrm{C}$ & 4 & 2 & 3 \\
\hline Ochoa et al. [36] & III & A & 4 & 0 & 4 \\
\hline Ousema and Nunley [37] & II & $\mathrm{C}$ & 2 & 10 & 6 \\
\hline Ozer et al. [38] & III & $\mathrm{C}$ & 4 & 0 & 4 \\
\hline Palmanovich et al. [39] & III & A & 0 & 0 & 3 \\
\hline Patterson et al. [40] & III & B & 1 & 5 & 6 \\
\hline Pelet et al. [41] & III & $\mathrm{D}$ & 6 & 4 & 5 \\
\hline Pelligrini et al. [42] & III & $\mathrm{C}$ & $2+4$ & 0 & 5 \\
\hline Philbin et al. [43] & I & $\mathrm{A}, \mathrm{B}, \mathrm{C}, \mathrm{D}$ & 10 days $+4-6$ weeks & $4-6$ & 8 \\
\hline Radice et al. [44] & III & B & 5 & 0 & 5 \\
\hline Rapley et al. [45] & II & $\mathrm{C}$ & 1 & 5 & 1 \\
\hline Redfern and Myerson [46] & II & $\mathrm{B}, \mathrm{C}$ & 6 & 6-8 (max. 3 months) & 0 \\
\hline Ritter et al. [47] & $\mathrm{I}$ & $\mathrm{A}, \mathrm{B}, \mathrm{C}, \mathrm{D}$ & $2+2$ & 2 & $2-4$ \\
\hline Ross et al. [48] & III & A & 2 & 3 & - \\
\hline \multirow[t]{2}{*}{ Sammarco [49] } & I & A, B & 2 & 2 & 3 \\
\hline & & $\mathrm{C}$ & 4 & $2-3$ & $6-7$ \\
\hline \multirow[t]{2}{*}{ Sammarco [50] } & II & A & 3 & 0 & 3 \\
\hline & & $\mathrm{C}$ & 4 & 2 & \\
\hline Saxena and Pham [53] & II & A & $2-3$ & 2 & 2 \\
\hline Saxena and Wolf [54] & II & B & 3 & 3 & 6 \\
\hline Shoda et al. [56] & III & A & 6 & 0 & - \\
\hline Squires et al. [61] & I & A, B, C & 6 & 4 & 3 \\
\hline Stockton et al. [62] & II & A, B & 4 & $4+4$ & 12 \\
\hline Vega et al. [65] & I & A & 2 & 0 & 2 \\
\hline
\end{tabular}


Table 1 continued

\begin{tabular}{llllll}
\hline Study & Study design & Treatment & NWB in weeks & WB (partial) in weeks & Start ROM (weeks) \\
\hline Verheyen et al. [66] & III & D & 2 & 6 & - \\
Waldecker et al. [67] & III & B & 6 & 0 & 6 \\
Wapner et al. [69] & II & A, B, C & 0 & 3 & 3 \\
\hline
\end{tabular}

Study design: $I$ review/descriptive paper, $I I$ case series, $I I I$ case report, treatment: $A$ debridement with or without suturing, $B$ tenodesis, $C$ grafting, $D$ end-to-end

${ }^{a}$ Reported on both technique A and B. Since results from technique A are already reported in an prior study from the same author, only the results from technique $B$ are included
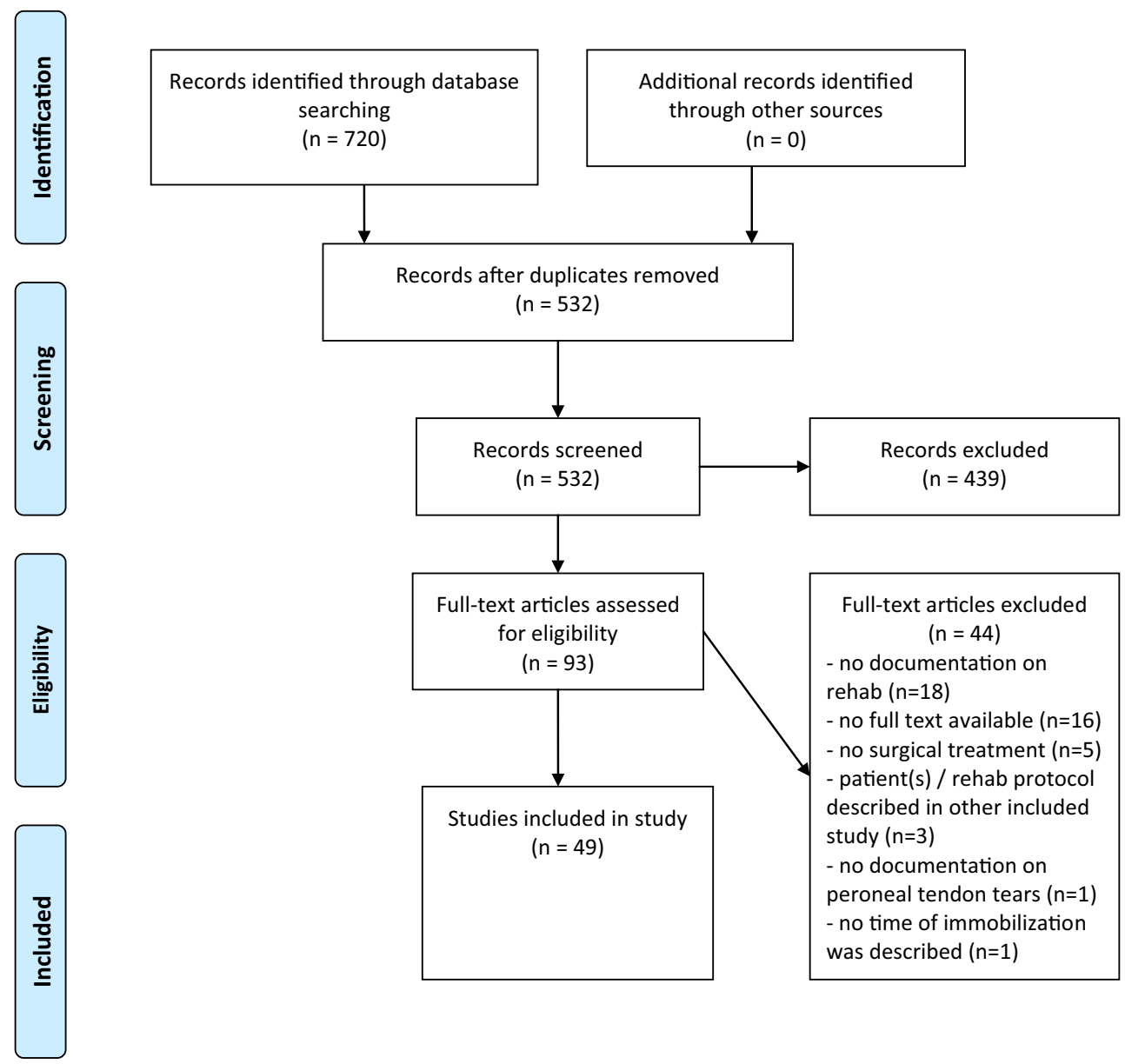

Fig. 1 PRISMA flow diagram [33]

surgical treatment methods: group A: primary repair with or without tubularization of the tendon, $[1,2,6,7,12-14,19$, 23-28, 31, 36, 39, 43, 47-50, 53, 56, 61, 62, 65, 69] group B: tenodesis, $[1,2,4,5,10,14,16,25,30,40,43,44,46$, $47,49,50,61,62,67,69]$ group C: grafting [8, 10, 21, 29, $34,37,38,42,43,45,46,49,50,61,69]$ and group D: endto-end suturing [1, 29, 41, 43, 47, 66, 68]. Fourteen studies reported two or more surgical treatment methods [10, 25, $29,43,46,47,49,50,61,62,69]$. Study characteristics and rehabilitation protocols are shown in Table 1.

\section{Rehabilitation after primary repair}

Twenty-eight studies reported on the rehabilitation protocol after primary repair of the peroneal tendons. Some of these also included performance of side-to-side suturing or tubularization $[1,2,6,7,12-14,19,23-28,31,36,39$, $43,47-50,53,56,61,62,65,69]$. The median duration of the immobilization period was 6.0 weeks (range 0-12) (Table 2). Of the studies $(n=23)$ that reported on the start of ROM exercises, 9 studies (39\%) started exercises 
Table 2 Overview of the non-weight-bearing and weight-bearing immobilization period and the moment of start with Range of Motion per treatment group

\begin{tabular}{lllll}
\hline & $\begin{array}{l}\text { Group A: primary repair } \\
(n=28)\end{array}$ & Group B: tenodesis $(n=21)$ Group C: grafting $(n=16)$ & $\begin{array}{l}\text { Group D: end-to-end sutur- } \\
\text { ing }(n=7)\end{array}$ \\
\hline $\begin{array}{l}\text { Total immobilization in } \\
\text { weeks }\end{array}$ & Median 6.0 (range 0-12) & Median 7.0 (range 3.0-13) & Median 6.3 (range 3.0-13) & Median 8.0 (range 6.0-11) \\
NWB in weeks & Median 3.5 (range 0-6.4) & Median 4.3 (range 0-8.0) & Median 4.0 (range 0-8.0) & Median 4.0 (range 2.0-8.0) \\
WB in weeks & Median 2.3 (range 0-8.0) & Median 3.0 (range 0-8.0) & Median 2.8 (range 0-10) & Median 4.0 (range 0-6.0) \\
Start ROM in weeks & $n=23^{\mathrm{a}}$ & $n=20^{\mathrm{a}}$ & $n=15^{\mathrm{a}}$ & $n=4^{\mathrm{a}}$ \\
& Median: 4.0 (range 2.0-12) & Median: 4.5 (range 0-12) & Median: 4.0 (range 0-12) & Median: 5.5 (range 2.0-8.0) \\
\hline
\end{tabular}

$N W B$ non-weight bearing, $W B$ weight bearing, $R O M$ range of motion

${ }^{a}$ Number of studies that reported on the start of range of motion after surgery

within 4 weeks post-operative $[23,39,47,49,50,53,61$, 65, 69].

\section{Rehabilitation after tenodesis}

Rehabilitation after tenodesis was reported in 21 studies [1, $2,4,5,10,14,16,25,30,40,43,44,46,47,49,50,54$, $61,62,67,69]$. The median duration of immobilization was 7.0 weeks (range 3.0-13) (Table 2). Of the studies $(n=20)$ that reported on the start of ROM exercises, 9 studies (45\%) started exercises within 4 weeks post-operative [5, $10,16,30,46,47,49,61,69]$.

\section{Rehabilitation after grafting}

Rehabilitation after surgical treatment with grafting was reported in 16 studies [8, 10, 21, 29, 34, 37, 38, 42, 43, $45,46,47,49,50,61,69$ ] with a median immobilization period of 6.3 (range 3.0-13) weeks (Table 2). Of the studies $(n=15)$ that reported on the start of ROM, 7 studies (47\%) reported on a start within 4 weeks post-operative [10, 34, 45-47, 61, 69].

\section{Rehabilitation after end-to-end suturing}

Seven studies [1, 29, 41, 43, 47, 66, 68] described the rehabilitation method after tendon end-to-end suturing technique. The median immobilization period was 8.0 weeks (range 6.0-11) (Table 2). Of the studies $(n=4)$ reporting on the start of ROM, 1 study (25\%) started exercises within 4 weeks post-operative [47].

\section{Comparison of groups}

There was no difference with respect to the total duration of immobilization between the different treatment groups (n.s.). Furthermore, when NWB and WB duration rates among different treatment groups were compared, no difference was found (n.s.).

\section{Discussion}

The most important finding of this study was that there exists a wide variation in rehabilitation protocols provided after surgical treatment of peroneal tendon tears and ruptures, confirming that there is no consensus among foot and ankle providers. No difference could be found in postoperative protocols between different treatment options. In recent years, there seems to be a trend towards early ROM and rehabilitation within 4 weeks post-operative [13, 23, 24]. However, it is difficult to formulate conclusions based on these data since current literature lacks studies that were primarily designed to study specific rehabilitation methods.

Peroneal tendon injuries are common in active patients. For this patient population, early return to activity and sports is of great importance. Since peroneal tendon tears and ruptures are protracted injuries, surgical repair merely marks the beginning of a long recovery period. Adequate rehabilitation is purported as an important aspect of the clinical success of any operatively treated tendon injury. A properly directed rehab programme can facilitate tendon healing, minimize scarring and promote early return to pre-injury activity/sports levels. Great attention should therefore be paid to determining the optimal post-operative treatment protocol.

Many rehabilitation recommendations have been published over the past decade regarding flexor tendons of the hand [18]. Flexor tendons are predisposed to forming adhesions between the repair and surrounding tissue, leading to scar, loss of ROM and limitation of tendon gliding. To prevent adhesion formation, early ROM is recommended $[3,11,15,52]$. Different authors have also advocated early 


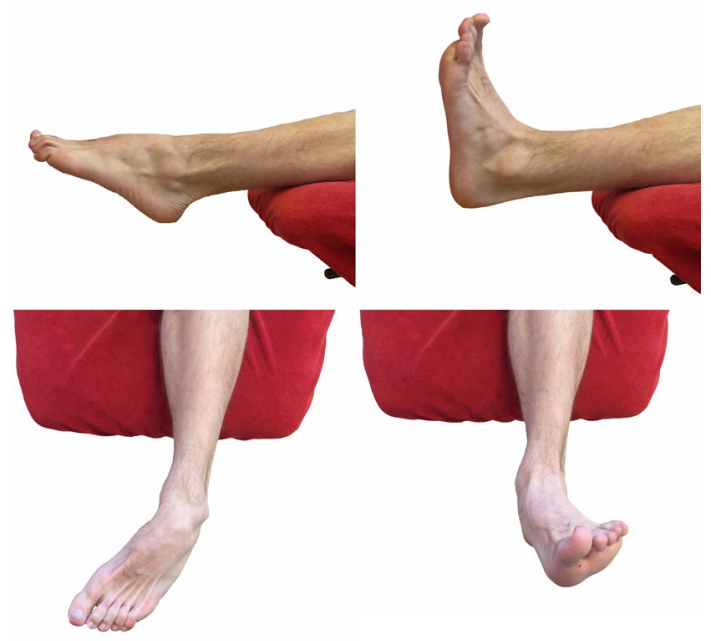

Fig. 2 Patient can start with active full ROM exercises: dorsiflexion, plantar flexion, inversion, eversion post-operative rehabilitation after Achilles tendon surgery $[20,22,35,60,63]$. A recent change to early ROM exercises can be found in operatively treated patients with peroneal tendon injuries $[13,23]$. Demetracouplos et al. and Karlsson et al. [13, 23, 24] have recently described a change in their post-operative management based on this information. In contrast to a previous protocol of 6 weeks cast immobilization followed by physical therapy, Demetracouplos et al. [13] implemented a post-operative protocol aiming early ROM after 4 weeks of WB and NWB immobilization. Karlsson et al. [23, 24] immobilized the patient 6 weeks in a plaster cast, but shortened the period in a study published 4 years later to 2 weeks plaster cast followed by a WB air cast brace to provide early ROM training.

Among the available studies analysed, we found wide variation in the total immobilization period. While some authors preferred early ROM without post-operative immobilization, [39] others immobilized their patients over

Fig. 3 Strength exercises: using the RSQ1 for electrical stimulation. In the second phase you can use this device during isometric or isotonic exercises
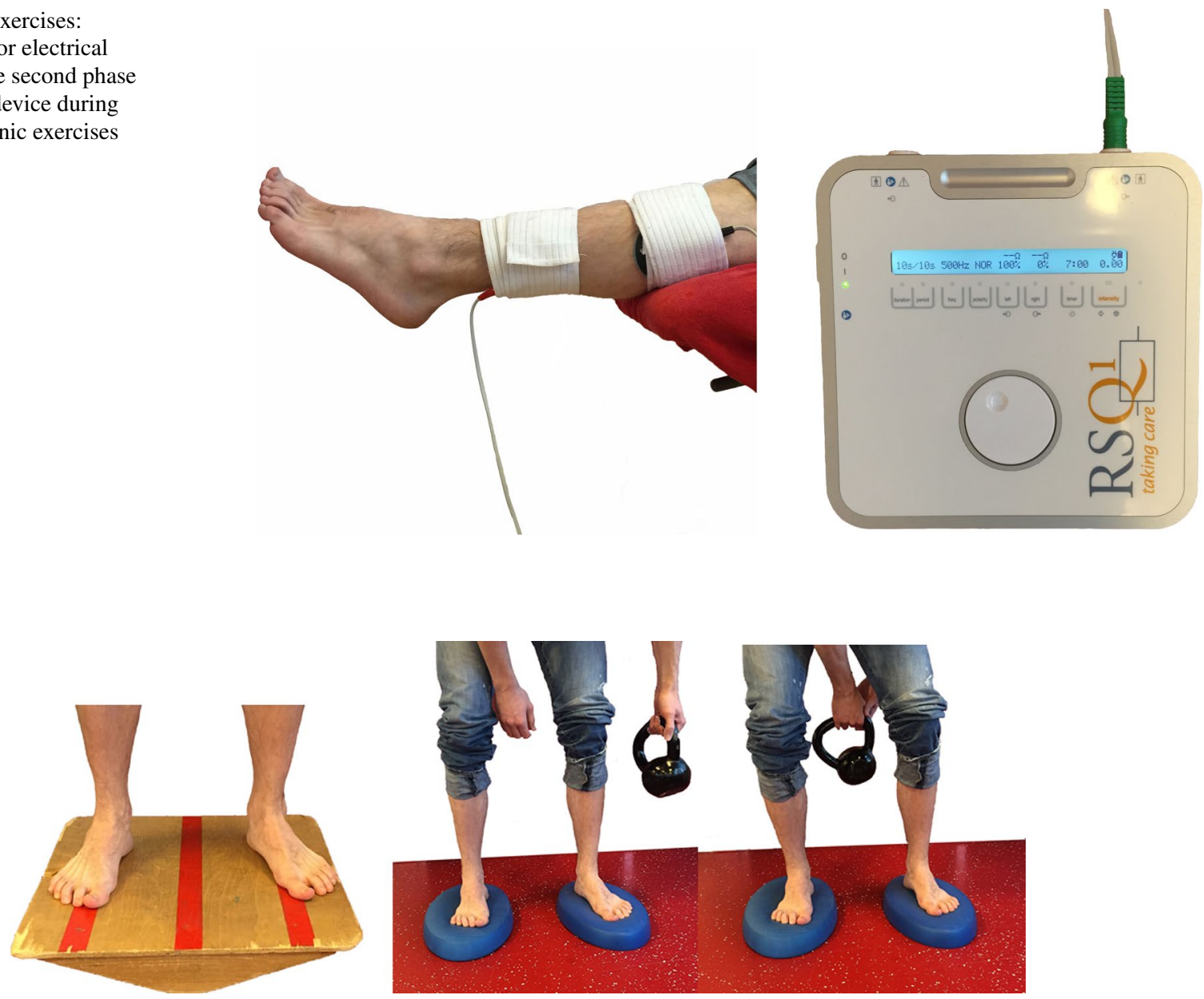

Fig. 4 Proprioceptive training: progress from NWB/controlled WB on two legs to full WB on unstable surfaces 
Fig. 5 Single leg balance activities (stable to unstable surfaces, without and with distractions)
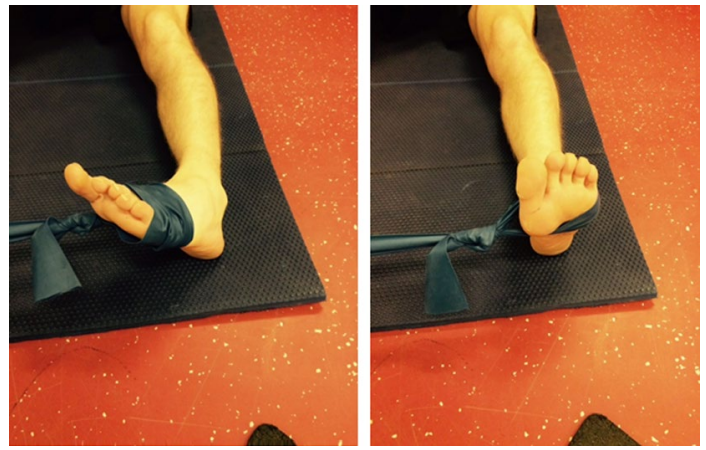

Fig. 6 Strength exercises: eversion against theraband. This is one of the most important exercises

12 weeks [46]. Due to the wide range found for this period of inactivity (0-13 weeks) among different studies, it is hard to draw conclusions and propose an evidence-based rehabilitation protocol. Based on our own experience, we recommend that an ideal peroneal rehabilitation protocol should be tailored according to individual patients needs and should be dependent upon the exact nature of tendon injury as well as the functional expectations of each patient.

This study has a few limitations. First, the clinical heterogeneity and small patients numbers among the included
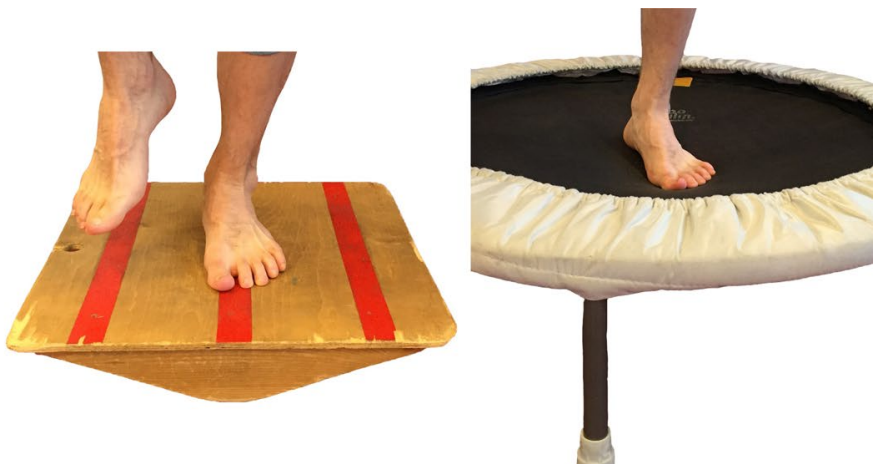

studies withholds us from drawing hard conclusions and therefore establishing an evidence-based protocol. Secondary, the results of this study were based on reviews and studies with the primary focus on the operative treatment of these ruptures. These methodological limitations prevented highquality conclusions based on synthesis of the available evidence. Therefore, our results provide an overview on the daily affairs in clinic and do not provide a sufficiently evidencebased recommendation and thus no statement can be made on the effectiveness of the rehabilitation protocols currently being employed. Our analysis, however, is based on best available evidence suggesting broad variation between different surgeons and lack of any consensus on a post-operative peroneal protocol. Finally, the search we performed yielded a relatively large amount of unavailable manuscripts.

\section{Proposed rehabilitation programme}

In order to come up with an evidence-based algorithm for the rehabilitation of peroneal disorders in daily clinical practice, a programme is proposed based on evaluation of available protocols described in today's literature as well as personal experience of the centres involved in this study. It is emphasized that this protocol will ultimately require validation.
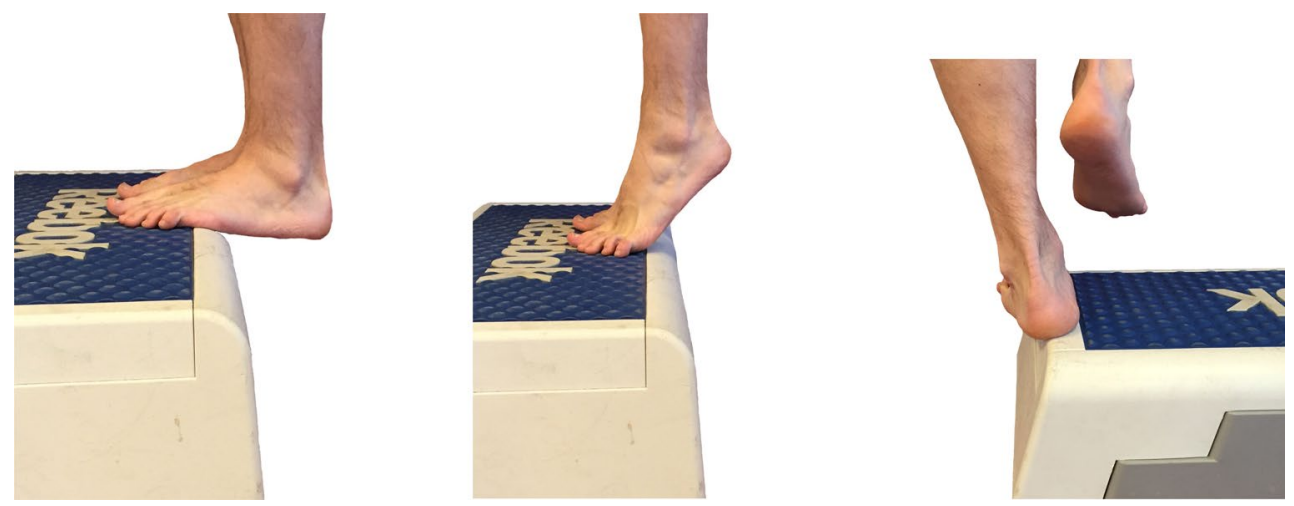

Fig. 7 Training of the strength of the foot and calf muscles 


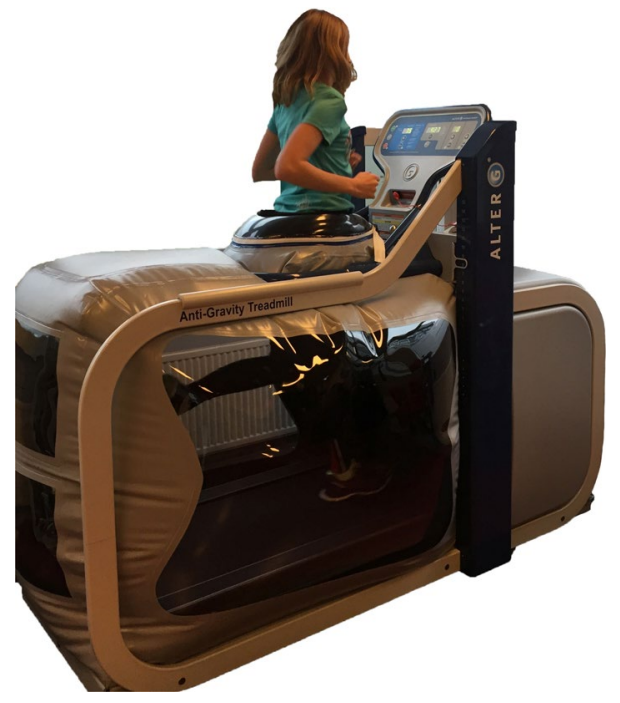

Fig. 8 Walking in an Alter-G trainer

Following surgical treatment of peroneal tendon tears, patients should receive a post-operative lower leg splint for 2 days, followed by 12 days of a NWB lower leg cast. After removal of the stitches, patients are then permitted to weight bear in a walker boot or lower leg cast for 4 weeks pending surgeon preference. Six weeks post-operative, physiotherapy is initiated to restore ROM (Fig. 2) and strength. Strength exercises include isometric exercises in pain free range and electrical stimulation of the peroneal muscles (Fig. 3). Simultaneously, proprioception and balance are trained by seated or partial WB exercises and proprioceptive exercises on two legs (Fig. 4). Proprioceptive exercises are gradually expanded from controlled WB on two legs to full
WB on two legs (Fig. 5). Eccentric, concentric and isotonic exercises are also started with the use of a theraband (Fig. 6). The strength of the foot and calf muscles is trained (Fig. 7), and the walking pattern is checked. Patients start to learn to walk again in a controlled setting either with use of an Alter-G trainer (Fig. 8) or a swimming pool in order to allow good motion in a partial WB setting to start with. This is helpful in preventing development of reactive peroneal tendinitis. No provocation of the peroneal tendons is allowed until 12 weeks post-operatively, and sports-specific rehabilitation is generally not initiated until at least 12 weeks of physiotherapy have concluded.

An overview of the proposed rehabilitation protocol is shown in Table 3. It is important to emphasize that the number of weeks are a median number of weeks and that each rehabilitation programme should be tailored according to individual patient needs, depending on both the exact nature of the peroneal problem as well as on the specific personal demands of the specific patient.

\section{Conclusion}

Rehabilitation is an important factor in the clinical success of all tendon injuries, and treatment of peroneal tendon tears and ruptures is no exception. There is no consensus in today's literature with regard to an ideal post-operative immobilization time or initiation of range of motion exercises. Prospective, randomized controlled trials are needed to refine optimal rehabilitation methods for patients with peroneal tendon tears or ruptures after operative treatment. Based on currently available data

Table 3 Overview of the proposed rehabilitation protocol of surgically treated peroneal tendon disorders, based on the evaluation of available protocols in literature

\begin{tabular}{|c|c|c|c|c|c|c|}
\hline & $0-2$ weeks $^{\mathrm{a}}$ & $2-4$ weeks $^{\mathrm{a}}$ & 6-8 weeks ${ }^{\mathrm{a}}$ & $8-12$ weeks $^{\mathrm{a}}$ & $12-24$ weeks $^{\mathrm{a}}$ & $>24$ weeks $^{\mathrm{a}}$ \\
\hline \multicolumn{7}{|l|}{ Weight bearing: } \\
\hline 1. Non-weight bearing & $\mathrm{x}$ & & & & & \\
\hline 2. Partial weight bearing & & $\mathrm{x}$ & $\mathrm{x}$ & & & \\
\hline 3. Full weight bearing & & & & $\mathrm{x}$ & $\mathrm{x}$ & $\mathrm{x}$ \\
\hline Active Range of Motion & & & $\mathrm{x}$ & & & \\
\hline Strength exercises & & & $\mathrm{x}$ & & & \\
\hline Proprioceptive training & & & $\mathrm{x}$ & $\mathrm{x}$ & & \\
\hline Eccentric/concentric exercises & & & & $\mathrm{x}$ & $\mathrm{x}$ & \\
\hline Isotonic exercises & & & & $x$ & $\mathrm{x}$ & \\
\hline Running & & & & & $\mathrm{x}$ & $\mathrm{x}$ \\
\hline Sport specific training & & & & & & $\mathrm{x}$ \\
\hline Provocation peroneal tendons & & & & & & $\mathrm{x}$ \\
\hline
\end{tabular}

${ }^{\text {a }}$ Number of weeks after operation 
and a combined personal clinical experience exceeding 50 years, a tailored rehabilitation protocol for every specific patient is advised for optimal functional recovery and prevention of re-rupture.

Open Access This article is distributed under the terms of the Creative Commons Attribution 4.0 International License (http://creativecommons.org/licenses/by/4.0/), which permits unrestricted use, distribution, and reproduction in any medium, provided you give appropriate credit to the original author(s) and the source, provide a link to the Creative Commons license, and indicate if changes were made.

\section{References}

1. Arbab D, Tingart M, Frank D, Abbara-Czardybon M, Waizy $\mathrm{H}$, Wingenfeld C (2014) Treatment of isolated peroneus longus tears and a review of the literature. Foot Ankle Spec 7:113-118

2. Bare A, Ferkel RD (2009) Peroneal tendon tears: associated arthroscopic findings and results after repair. Arthroscopy 25:1288-1297

3. Becker H, Orak F, Duponselle E (1979) Early active motion following a beveled technique of flexor tendon repair: report on fifty cases. J Hand Surg Am 4:454-460

4. Berg EE (1996) Intraoperative peroneus brevis tendon rupture: a technique to salvage the graft during ankle ligament reconstruction. Foot Ankle Int 17:349-351

5. Blitz NM, Nemes KK (2007) Bilateral peroneus longus tendon rupture through a bipartite os peroneum. J Foot Ankle Surg 46:270-277

6. Bonnin M, Tavernier T, Bouysset M (1997) Split lesions of the peroneus brevis tendon in chronic ankle laxity. Am J Sports Med 25:699-703

7. Borland S, Jung S, Hugh IA (2009) Complete rupture of the peroneus longus tendon secondary to injection. Foot 19:229-231

8. Borton DC, Lucas P, Jomha NM, Cross MJ, Slater K (1998) Operative reconstruction after transverse rupture of the tendons of both peroneus longus and brevis. Surgical reconstruction by transfer of the flexor digitorum longus tendon. J Bone Joint Surg Br 80:781-784

9. Boruta PM, Bishop JO, Braly WG, Tullos HS (1990) Acute lateral ankle ligament injuries: a literature review. Foot Ankle 11:107-113

10. Cerrato RA, Campbell JT (2009) Tenodesis and transfer procedures for peroneal tears and tendinosis. Tech Foot Ankle Surg $8: 119-125$

11. Cullen KW, Tolhurst P, Lang D, Page RE (1989) Flexor tendon repair in zone 2 followed by controlled active mobilisation. J Hand Surg Br 14:392-395

12. De Yoe BE, Ng A, Miller B, Rockett MS (1999) Peroneus brevis tendon rupture with tophaceous gout infiltration. J Foot Ankle Surg 38:359-362

13. Demetracopoulos CA, Vineyard JC, Kiesau CD, Nunley JA (2014) Long-term results of debridement and primary repair of peroneal tendon tears. Foot Ankle Int 35:252-257

14. Dombek MF, Lamm BM, Saltrick K, Mendicino RW, Catanzariti AR (2003) Peroneal tendon tears: a retrospective review. J Foot Ankle Surg 42:250-258

15. Elliot D, Giesen T (2013) Avoidance of unfavourable results following primary flexor tendon surgery. Indian J Plast Surg 46:312-324

16. Fujioka H, Kokubu T, Makino T, Nagura I, Maeda T, Kurosaka M, Okuno H, Yamagiwa T, Tanaka J, Yoshiya S (2009)
Subcutaneous peroneus longus tendon rupture associated with OS peroneum fracture. J Sports Sci Med 8:705-708

17. Geller J, Lin S, Cordas D, Vieira P (2003) Relationship of a lowlying muscle belly to tears of the peroneus brevis tendon. Am J Orthop (Belle Mead NJ) 32:541-544

18. Griffin M, Hindocha S, Jordan D, Saleh M, Khan W (2012) An overview of the management of flexor tendon injuries. Open Orthop J 6:28-35

19. Ho KK, Chan KB, Lui TH, Chow YY (2013) Tendoscopicassisted repair of complete rupture of the peroneus longus associated with displaced fracture of the os peroneum-case report. Foot Ankle Int 34:1600-1604

20. Jielile J, Badalihan A, Qianman B, Satewalede T, Wuerliebieke J, Kelamu M, Jialihasi A (2015) Clinical outcome of exercise therapy and early post-operative rehabilitation for treatment of neglected Achilles tendon rupture: a randomized study. Knee Surg Sports Traumatol Arthrosc. doi:10.1007/ s00167-015-3598-4

21. Jockel JR, Brodsky JW (2013) Single-stage flexor tendon transfer for the treatment of severe concomitant peroneus longus and brevis tendon tears. Foot Ankle Int 34:666-672

22. Kangas J, Pajala A, Ohtonen P, Leppilahti J (2007) Achilles tendon elongation after rupture repair: a randomized comparison of 2 postoperative regimens. Am J Sports Med 35:59-64

23. Karlsson J, Wiger P (2002) Longitudinal split of the peroneus brevis tendon and lateral ankle instability: treatment of concomitant lesions. J Athl Train 37:463-466

24. Karlsson J, Brandsson S, Kalebo P, Eriksson BI (1998) Surgical treatment of concomitant chronic ankle instability and longitudinal rupture of the peroneus brevis tendon. Scand J Med Sci Sports 8:42-49

25. Krause JO, Brodsky JW (1998) Peroneus brevis tendon tears: pathophysiology, surgical reconstruction, and clinical results. Foot Ankle Int 19:271-279

26. Lagoutaris ED, Adams HB, DiDomenico LA, Rothenberg RJ (2005) Longitudinal tears of both peroneal tendons associated with tophaceous gouty infiltration. A case report. J Foot Ankle Surg 44:222-224

27. Lucas DE, Hyer CF, Berlet GC, Shockley JA (2013) Anomalous peroneal tendon insertion masquerading as a retracted tendon tear: case report. Foot Ankle Int 34:603-606

28. Lui TH, Tse LF (2015) Peroneal tendoscopy. Foot Ankle Clin 20:15-25

29. Madsen BL, Noer HH (1999) Simultaneous rupture of both peroneal tendons after corticosteroid injection: operative treatment. Injury 30:299-300

30. Maurer M, Lehrman J (2012) Significance of sesamoid ossification in peroneus longus tendon ruptures. J Foot Ankle Surg $51: 352-355$

31. Minoyama O, Uchiyama E, Iwaso H, Hiranuma K, Takeda $\mathrm{Y}$ (2002) Two cases of peroneus brevis tendon tear. Br J Sports Med 36:65-66

32. Miura K, Ishibashi Y, Tsuda E, Kusumi T, Toh S (2004) Split lesions of the peroneus brevis tendon in the Japanese population: an anatomic and histologic study of 112 cadaveric ankles. J Orthop Sci 9:291-295

33. Moher D, Liberati A, Tetzlaff J, Altman DG, The PRISMA Group (2009) Preferred reporting items for systematic reviews and meta-analyses: the PRISMA statement. PLoS Med 6(6):e1000097. doi:10.1371/journal.pmed1000097

34. Mook WR, Parekh SG, Nunley JA (2013) Allograft reconstruction of peroneal tendons: operative technique and clinical outcomes. Foot Ankle Int 34:1212-1220

35. Motta P, Errichiello C, Pontini I (1997) Achilles tendon rupture. A new technique for easy surgical repair and immediate movement of the ankle and foot. Am J Sports Med 25:172-176 
36. Ochoa LM, Banerjee R (2007) Recurrent hypertrophic peroneal tubercle associated with peroneus brevis tendon tear. J Foot Ankle Surg 46:403-408

37. Ousema PH, Nunley JA (2010) Allograft replacement for peroneal tendon tears. Tech Foot Ankle 9:72-75

38. Ozer H, Oznur A (2005) Peroneal tendon repair with autologous hamstring tendons. J Foot Ankle Surg 44:487-489

39. Palmanovich E, Laver L, Brin YS, Hetsroni I, Nyska M (2014) Tear of peroneus longus in long distance runners due to enlarged peroneal tubercle. BMC Sports Sci Med Rehabil 6:1

40. Patterson MJ, Cox WK (1999) Peroneus longus tendon rupture as a cause of chronic lateral ankle pain. Clin Orthop Relat Res 365:163-166

41. Pelet S, Saglini M, Garofalo R, Wettstein M, Mouhsine E (2003) Traumatic rupture of both peroneal longus and brevis tendons. Foot Ankle Int 24:721-723

42. Pellegrini MJ, Adams SB, Parekh SG (2015) Allograft reconstruction of peroneus longus and brevis tendons tears arising from a single muscular belly. Case report and surgical technique. Foot Ankle Surg 21:e12-e15

43. Philbin TM, Landis GS, Smith B (2009) Peroneal tendon injuries. J Am Acad Orthop Surg 17:306-317

44. Radice F, Monckeberg JE, Carcuro G (2011) Longitudinal tears of peroneus longus and brevis tendons: a gouty infiltration. $\mathrm{J}$ Foot Ankle Surg 50:751-753

45. Rapley JH, Crates J, Barber A (2010) Mid-substance peroneal tendon defects augmented with an acellular dermal matrix allograft. Foot Ankle Int 31:136-140

46. Redfern D, Myerson M (2004) The management of concomitant tears of the peroneus longus and brevis tendons. Foot Ankle Int 25:695-707

47. Ritter C (2009) Acute peroneal tendon tears. Tech Foot Ankle $8: 106-111$

48. Ross G, Regan KJ, McDevitt ER, Wilckens J (1999) Rupture of the peroneus longus tendon in a military athlete. Am J Orthop (Belle Mead NJ) 28:657-658

49. Sammarco GJ (1994) Peroneal tendon injuries. Orthop Clin North Am 25:135-145

50. Sammarco GJ (1995) Peroneus longus tendon tears: acute and chronic. Foot Ankle Int 16:245-253

51. Sammarco GJ, DiRaimondo CV (1989) Chronic peroneus brevis tendon lesions. Foot Ankle 9:163-170

52. Savage R, Risitano G (1989) Flexor tendon repair using a "six strand" method of repair and early active mobilisation. J Hand Surg Br 14:396-399

53. Saxena A, Pham B (1997) Longitudinal peroneal tendon tears. J Foot Ankle Surg 36:173-179 (discussion 255)

54. Saxena A, Wolf SK (2003) Peroneal tendon abnormalities. A review of 40 surgical cases. J Am Podiatr Med Assoc 93:272-282
55. Selmani E, Gjata V, Gjika E (2006) Current concepts review: peroneal tendon disorders. Foot Ankle Int 27:221-228

56. Shoda E, Kurosaka M, Yoshiya S, Kurihara A, Hirohata K (1991) Longitudinal ruptures of the peroneal tendons. A report of a rugby player. Acta Orthop Scand 62:491-492

57. Sobel M, Bohne WH, Levy ME (1990) Longitudinal attrition of the peroneus brevis tendon in the fibular groove: an anatomic study. Foot Ankle 11:124-128

58. Sobel M, Geppert MJ, Olson EJ, Bohne WH, Arnoczky SP (1992) The dynamics of peroneus brevis tendon splits: a proposed mechanism, technique of diagnosis, and classification of injury. Foot Ankle 13:413-422

59. Sobel M, Geppert MJ, Warren RF (1993) Chronic ankle instability as a cause of peroneal tendon injury. Clin Orthop Relat Res 296:187-191

60. Solveborn SA, Moberg A (1994) Immediate free ankle motion after surgical repair of acute Achilles tendon ruptures. Am J Sports Med 22:607-610

61. Squires N, Myerson MS, Gamba C (2007) Surgical treatment of peroneal tendon tears. Foot Ankle Clin 12:675-695

62. Stockton KG, Brodsky JW (2014) Peroneus longus tears associated with pathology of the os peroneum. Foot Ankle Int 35:346-352

63. Uchiyama E, Nomura A, Takeda Y, Hiranuma K, Iwaso H (2007) A modified operation for Achilles tendon ruptures. Am J Sports Med 35:1739-1743

64. van Dijk PA, de Leeuw PA, Kerkhoffs GM (2014) Peroneal tendon disorders. vol Athletic injuries of the ankle, May 2014 edn. ESSKA, DVD-ESSKA

65. Vega J, Golano P, Batista JP, Malagelada F, Pellegrino A (2013) Tendoscopic procedure associated with peroneal tendons. Tech Foot Ankle 12:39-48

66. Verheyen CP, Bras J, van Dijk CN (2000) Rupture of both peroneal tendons in a professional athlete. A case report. Am J Sports Med 28:897-900

67. Waldecker U (2005) Unusual location of a posttraumatic ganglion and rupture of the peroneus brevis tendon: a case report. J Foot Ankle Surg 44:163-165

68. Wang KC, Tu YK, Fang CM, Liu HT, Ueng SW (2004) Talar body fracture combined with traumatic rupture of anterior talofibular ligament and peroneal longus tendon. Chang Gung Med J 27:56-60

69. Wapner KL, Taras JS, Lin SS, Chao W (2006) Staged reconstruction for chronic rupture of both peroneal tendons using Hunter rod and flexor hallucis longus tendon transfer: a long-term followup study. Foot Ankle Int 27:591-597 